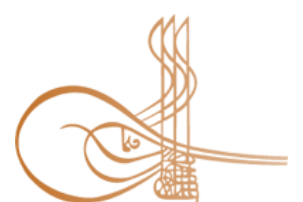

www.turkishstudies.net/economy
Turkish Studies - Economics, Finance, Politics

eISSN: $2667-5625$

Research Article / Araștırma Makalesi

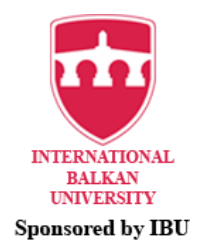

Sponsored by IBU

\title{
Türkiye'de Spor Ekonomisi Alanında Yayımlanan Muhasebe-Finans Temalı Makalelerde Metodolojik Eğilimler
}

\author{
The Methodological Trends in Accounting-Finance Themed Articles Published in the Field of \\ Sports Economy in Turkey
}

\author{
Engin Boztepe*- Ahmet Atalay ${ }^{* *}$
}

\begin{abstract}
Aim: The aim of this study is to examine the methodological tendencies of accounting finance themed articles published in Turkish in the field of sports economics in scientific journals in the DERGIPARK system and open to access between 2005 and 2020. Method: In this context, while the study was carried out with the qualitative research method, the case study pattern was used in this process and the analyzes were carried out with the content analysis method. Findings: In 43 studies examined, it was not determined which research method and pattern were used in almost all of the articles. It was determined that more than half of the studies were studied with the entire universe (sports clubs) rather than choosing samples, and it was determined that document analysis was preferred as a data collection tool. Because the studies can be said to be based on the examination and evaluation of the financial statements of sports clubs. In analysis of the data, it is seen that along with financial analysis methods, such as ANOVA, Regression and TOPSIS are used. Conclusion: It can be said that the methodological structures of the studies conducted in the field of sports economy are incomplete and inadequate, methodological fictions are not conveyed clearly and clearly, especially when compared to other fields, scientific research methods and techniques cannot be used effectively. It can be said that the methodological structures of the studies on sports economics are weak, especially when compared to the methodological studies in the fields of education, social and science. In order to strengthen the qualitative structure of the literature, it is essential to use scientific research methods more effectively. In this context, it is expected that this research will provide more comprehensive and descriptive information in the field of sports sciences in future studies.
\end{abstract}

Structured Abstract: The main purpose of the academics in universities is to provide education at the undergraduate and graduate levels, while contributing to the academic literature and conducting scientific studies. Academic studies and research are important for all fields of science, which is even more important for rapidly and effectively developing disciplines (Skinner et al., 2015: 5). So much so that there is a need for special and advanced research in sports management, which is a special discipline and developing rapidly

\footnotetext{
* Dr. Öğr. Üyesi, Ardahan Üniversitesi, Sağlık Bilimleri Yüksekokulu, Sağlık Yönetimi Bölümü Assistant Prof., Ardahan University, School of Health Sciences, Department of Health Management ORCID 0000-0003-0775-6129 enginboztepe@ardahan.edu.tr

** Doç. Dr., Ardahan Üniversitesi, Beden Eğitimi ve Spor Yüksekokulu, Spor Yöneticiliği Bölümü Associate Prof., Ardahan University, School of Physical Education and Sport, Department of Sport Management. ORCID 0000-0003-0263-1677

ahmetatalay@ardahan.edu.tr

Cite as/ Atıf: Boztepe Engin \& Atalay, A. (2020). Türkiye'de spor ekonomisi alanında yayımlanan muhasebe-finans temalı makalelerde metodolojik eğilimler. Turkish Studies - Economy, 15(3), 1233-1246. https://dx.doi.org/10.47644/TurkishStudies.41870

Received/Geliş: 20 February/Şubat 2020

Accepted/Kabul: 20 September/Eylül 2020

Copyright C INTAC LTD, Turkey
} 
(Chalip, 2006). In order to meet this need, sports economy, which is one of the sub-disciplines of sports management, has come to the fore in recent years. Because, it is seen that various scientific studies are carried out on financial performance analysis of football clubs (Uluyol, 2014). As a matter of fact, Cunningham and Mahoney (2004) states that quantitative studies in these areas have been carried out frequently in recent years.

Many articles in scientific journals related to sports economy and sub-disciplines are published in Turkey. This is very important for the examination of the sports economy in the academic medium. However, in the process of establishing a balance of quality and quantity and enriching the literature of sports economics, it is essential to consider qualitative development together with quantitative progress. One of the premises of qualitative progress or evaluation is that the methodological fictions of these publications are based on scientific foundations and have a complete and error-free structure. One of the most important criteria in qualified scientific publications is the methodological structure. A methodologically erroneous or incompletely edited study can be considered totally false or incomplete. Therefore, the method sections of the published articles must be created correctly and transferred clearly and understandable to the reader (Atalay, 2017). Therefore, examining and examining the methodological structures of scientific studies can shed light on whether the literature is formed in a healthy way.

Purpose of the research

The aim of this study is to investigate the methodological tendencies of accounting finance themed articles published in Turkish in the field of sports economics in scientific journals in the DERGIPARK system and open to access between 2005 and 2020.

\section{Research Model}

In the academic literature, it can be said that the interest in qualitative research has increased recently in the field of social sciences. In this context, while the study was carried out with the qualitative research method, the case study pattern was used in this process and the analyzes were carried out with the content analysis method.

\section{Result}

In this study, in which the methodological tendencies of accounting finance themed articles published in Turkish in the field of sports economics in scientific journals in the DERGIPARK system and open to access, the following conclusions were reached:

- In 42 of the 43 articles whose method sections have been examined, there is not any information about which research method is used and which research pattern is used in 40 of them. In addition, 23 studies did not go through the selection of samples and the entire universe was reached.

- In the studies, mostly sports clubs were determined as the sample group and financial statements of these clubs were examined.

- In the articles, it is determined that the document analysis method is preferred as the data collection tool for the purpose of analyzing the financial statements.

- In the analysis of the data obtained, ANOVA, Regression and TOPSIS methods were preferred as well as financial analysis methods (Littlewood two class model, EGARCH, Entropy analysis and Head-to-head model analysis).

It can be said that the methodological structures of accounting finance themed studies in the field of sports economy are inadequate and incomplete. In particular, the lack of information about which research method and pattern is used weakens the methodological structure of the studies. As a matter of fact, Tuncel (2008) supports this conclusion and states that in scientific studies produced in sports sciences, the method part is not presented completely, and most of the time, appropriate research methods are not used. It can be said that the methodological structure of the studies related to the sports economy is weak compared to the methodological studies in the fields of education, social and science. It is essential to use scientific research methods more effectively in order to strengthen the qualitative structure of the literature.

Keywords: Sport, Economy, Finance, Accounting, Content Analysis. 
Öz: Amaç: Bu çalışmanın amacı, DERGiPARK sisteminde yer alan ve erişime açık olan bilimsel dergilerde 2005-2020 yılları arasında spor ekonomisi alanında Türkçe yayımlanan muhasebe finans temalı makalelerin yöntemsel eğilimlerini incelemektir. Yöntem: Bu bağlamda çalışma nitel araştırma yöntemiyle yürütülürken bu süreçte durum çalışması deseninden yararlanılmış olup analizler ise içerik analizi yöntemi ile gerçekleştirilmiş̧ir. Bulgular: İncelenen 43 çalışmada makalelerin neredeyse tamamında hangi araştırma yönteminin ve deseninin kullanıldığının belirtilmediği saptanmıştır. Örneklem seçmekten ziyade çalışmaların yarısından fazlasında evrenin tamamı ile çalışılırken (spor kulüpleri) veri toplama aracı olarak doküman incelemenin tercih edildiği belirlenmiştir. Zira çalışmaların spor kulüplerine ait finansal tabloların incelenmesi ve değerlendirilmesi üzerine kurgulandığı söylenebilir. Verilerin analizinde ise finansal analiz yöntemleri ile birlikte ANOVA, Regresyon ve TOPSIS gibi analizlerin kullanıldığı görülmektedir. Sonuç: Spor ekonomisi alanında yapılan çalışmaların metodolojik yapılarının eksik ve yetersiz kaldığı, yöntemsel kurguların açık ve net bir şekilde aktarılmadığı, özellikle diğer alanlarla kıyaslandığında oldukça bilimsel araştırma yöntem ve tekniklerinin etkin bir şekilde kullanılamadığı söylenebilir. Özellikle eğitim, sosyal ve fen bilimleri alanlarında yer alan metodolojik inceleme çalışmaları ile kıyaslandığında spor ekonomisi ile ilgili çalışmaların yöntemsel yapılarının zayıf kaldığı söylenebilir. Literatürün niteliksel yapısının güçlendirilmesi adına bilimsel araştırma yöntemlerinin daha etkili bir şekilde kullanılmass elzemdir. Bu bağlamda, yürütülen bu araştırma özelinde daha sonra yapılacak çalışmalarında spor bilimleri alanında daha kapsamlı ve tanımlayıcı bilgiler sunması beklenmektedir.

Anahtar Kelimeler: Spor, Ekonomi, Finans, Muhasebe, İçerik Analizi.

\section{Giriş}

Bireylerin sağlıklı kalmaları ve uzun süren bir yaşam sürecine katkı sunması sosyalleşme ve ekonomik olarak iyi olma halini etkilemesi, milletlerin siyasi başarılarında belirleyici olması, global dünyada bir marka olması ve nitelikli ve sağlıklı bir toplumun inşasında (Bayraktar, 2003; Türkmen ve Varol, 2017; Devecioğlu, 2005; Yetim, 2000; Deery and Jogo, 2005; Ayan ve Ergin, 2017; Darnell, 2010) sporun bir bilim dalı olarak değerlendirilmesi, gelişmesi ve ortak bir değere dönşmesinde belirleyici olmuştur. Dolayısıyla spor, bir bilim dalı olarak gelirişiken ülkelerin eğitim sistemleri içerisnde kendisine yer edinmiş, uyuglama ve teoride bilim insanları ve uygulayıcıların dikkatini çekmiştir. (Yiamauyiannis vd., 2013; Pitney vd., 2002; Miragaia and Soares, 2017). Düzenli fiziksel aktivite, insan sağlı̆̆ ve uzun yaşam üzerine olumlu etkiler gösterir (Ayan ve Ergin, 2017). Spora dair yapılan ilk ve temel tanımların başında yukarıda yer alan ifade gelmektedir. Ancak günümüzde spor yönetimi bünyesinde bir alt disiplin olarak spor ekonomisi de oldukça önemli bir alan haline gelmiştir. Bugün spor salt sağlık ve eğlence aracı olmaktan çıkmış, milyar dolarlık hacmi ile devasa bir endüstriye evrilmiştir. Özellikle futbol, milyonlarca dolar yatırım yapılan, hitap ettiği sayısal olarak devasa boyuta erişen taraftarı ve ekonomik hacmi ile küresel gösteri sektörüne dönüşmüştür (Köylü vd., 2017). Yüksek bütçeli futbol kulüpleri profesyonelleşme ve şirketleşme yoluyla endüstriyel gelişime ayak uydurmaktadır (Güngör ve Kocamış, 2018).

Üniversitelerde yer alan akademisyenlerin temel amacı lisans ve lisansüstü düzeyde eğitim vermekle birlikte akademik literatüre katkı sağlamak ve bilimsel çalışmalar yürütmektir.

Bilimsel veriler ışığında yürütülen akademik çalışmalar tüm bilimsel disiplinler için önemlidir, bununla birlikte son dönemerde popüler hale gelen disiplinler için bu önem bir kat daha artmaktadır (Skinner vd., 2015:5). Öyle ki, son yıllarda popüler haen gelen spor bilimlerinde de kapsamlı ve nitelikli çalışmalarında yürütülmesi önem kazanmıştır (Chalip, 2006). Bu öneme bağlı olarak spor yönetiminin alt disiplinlerinden biri olan spor ekonomisi öne çıkmaktadır. Zira futbol takımlarının mali yapılarına ve performanslarına ilişkin analizlerin ortaya konulduğu bilimsel araştırmalar mevcuttur (Uluyol, 2014). Nitekim Cunningham and Mahoney (2004)'de spor ekonomisi alanında son yıllarda önemli bilimsel çalışmaların yürütüldügünü ifade etmektedir. 


\section{Araştırmanın Önemi}

Öyle ki futbol endüstrisinin ticari satışlar, sponsorluk anlaşmaları ve maç hâsılatları gibi kendi içinde gelir kalemleri dahi bulunmaktadır. (Scholtens ve Peenstra, 2009). Sporun ve özellikle futbolun bu ekonomik gelişimi, hem teoride hem de uygulamada birçok araştırmacının ilgisini çekmiştir. Özellikle üniversitelerde çalışan, spor ve sosyal bilimciler sporun endüstriyel yapısına bilimsel çalışmalar ile ışık tutmaya çalışmaktadır. Nitekim akademik kimliği olan kişilerin literatüre yapacağ1 katkılar bu çalışmalar ile mümkün olmaktadır. Akademisyenlerin kişisel ve mesleki gelişimlerini sürekli besleyerek belirli bir düzeye gelmesi de oldukça önemlidir. Bu konuda Karakaya ve Tel (2014), akademisyenlerin mesleki olarak gelişmesi ve uluslararası camiada yer edinmeleri gerektiğini belirtmektedir.

Türkiye'de bilimsel dergilerde spor ekonomisi ve alt disiplinlerine ilişkin birçok makale yayımlanmaktadır. Bu durum spor ekonomisinin akademik mecrada incelenmesi adına oldukça önemlidir. Ancak nitelik ve nicelik dengesinin kurulması ve spor ekonomisi literatürünün zenginleştirilmesi sürecinde nicel ilerlemeyle birlikte nitel gelişimin de titizlikle ele alınması elzemdir. Niteliksel ilerlemenin veya değerlendirmenin öncüllerinden birisi de bu yayınların metodolojik kurgularının bilimsel temellere dayanması, eksiksiz ve hatasız bir yapı arz etmesidir.

\section{Araştırmanın Amacı}

$\mathrm{Bu}$ çalışmanın amacı, DERGIPARK sisteminde yer alan ve erişime açık olan bilimsel dergilerde 2005-2020 yılları arasında spor ekonomisi alanında Türkçe yayımlanan muhasebe finans temalı makalelerin yöntemsel eğilimlerini incelemektir. Buna yönelik olarak aşağıda yer alan araştırma sorularına cevaplar aranmıştır.

\begin{tabular}{ll}
\multicolumn{1}{c}{ Tablo 1: Araştırma Soruları } \\
\hline & Yıllara göre çalışmaların dağılımı nasıldır? \\
& Üniversitelere göre çalışmaların dağılımı nasıldır? \\
& Akademisyen sayılarına göre çalışmaların dağılımı nasıldır? \\
\hline & Çalışmaların yöntemlerine göre dağılımı nasıldır? \\
& Araştırma desenine göre çalışmaların dağılımı nasıldır? \\
& Örnekleme modeline göre çalışmaların dağılımı nasıldır? \\
& Örneklem gruplarına göre çalışmaların göre dağılımı nasıldır? \\
& Veri toplama araçlarına göre çalışmaların dağılımı nasıldır? \\
& Çalışmaların analiz yöntemlerine göre dağılımı nasıldır? \\
\hline
\end{tabular}

\section{Araştırmanın Sınırlılıkları}

$\mathrm{Bu}$ araştırma, DERGIPARK sisteminde yer alan ve erişime açık olan bilimsel dergiler ile sınırlandırılmış; spor ekonomisinde meydana gelen gelişmeler dikkate alınarak son 15 yılda üretilen akademik makaleler incelenmiştir. Çalışma için DERGIPARK sisteminde yer alan toplam 30 dergiye ulaşılmış ve 43 makale incelenmiştir. Bununla birlikte çalışmaların analiz sürecinde makalelerin sadece materyal ve metot kısımları dikkate alınmıştır. Her ne kadar çalışmaların bulgular kısmında makalelerin metodolojik yapılarına ilişkin bilgiler ve ipuçları olsa da herhangi bir çıkarımda bulunulmamıştır. Özetle analizlerde sadece materyal ve metot kısımları dikkate alınmıştır. 


\section{Yöntem}

\section{Araştırma Modeli}

Akademik literatürde sosyal bilimler alanında son zamanlarda nitel araştırmalara olan ilginin arttığı söylenebilir. Bu bağlamda çalışma nitel araştırma yöntemiyle yürütülürken bu süreçte durum çalışması deseninden yararlanılmış olup analizler ise içerik analizi yöntemi ile gerçekleştirilmiştir.

Karadağ (2010), nitel araştırmalarda tek tek parçalardan tekbir bütüne doğru bir yolun izlendiğini belirtmektedir. Durum çalışması deseni ise popüler bir metayı farklı yönleri ile ele alırken sistematik ve kapsamlı bir şekilde değerlendirmeye imkan sunmakta ve bu çalışmalarda verileri toplama yönteminin ise mevcut alan yazındır (Yıldırım ve Şimşek, 2016, s. 67). İçerik analizi yöntemi ise alan yazının detaylı olara değerlendirebilmeyi ve verilerin objektif ve sistemli olarak yorumlanmasına imkan sağlar (Falkingham ve Reeves, 1998; Tavşancıl ve Aslan, 2001:48).

\section{Evren-Örneklem}

Çalışmanın evrenini DERGIPARK sisteminde yer alan ve erişime açık olan bilimsel dergilerde 2005-2020 yılları arasında spor ekonomisi alanında Türkçe yayımlanan muhasebe finans temalı makaleler oluşturmaktadır. Araştırmada çalışma grubunun tamamına ulaşıldığı için örnekleme yoluna gidilmemiştir. Buna göre çalışmanın örneklemi de toplamda 30 dergide yayımlanan 43 makaleden oluşmaktadır.

\section{Veri Toplama Aracı}

Çalışmada Gökmen vd., (2017) tarafından geliştirilen "uzaktan eğitim tezleri inceleme formu"nun araştırmacılar tarafından, çalışmanın amacına uygun bir şekilde düzenlenmesi ile oluşturulan "spor ekonomisi ile ilgili makaleleri inceleme formu" kullanılmıştır.

\section{Verilerin Toplanması}

DERGIPARK sisteminde yer alan ve erişime açık olan bilimsel dergilerde yayımlanan spor ekonomisi alanında Türkçe yayımlanan muhasebe finans temalı makalelere ulaşmak için spor ekonomisi çalışma alanlarını kapsayan, halka arz, şirketleşme, borsa, muhasebe, spor kulübü, ișletme, finans, ekonomi, vb. anahtar kelimeler tespit edilmiștir. Daha sonra ise DERGIPARK sisteminde bu anahtar kelimeler ile kapsamlı bir tarama gerçekleştirilmiş ve 2005-2020 yılları arasında yayımlanan 43 çalışmaya ulaşılmıştır.

\section{Verilerin Analizi}

Spor ekonomisi ile ilgili muhasebe finans temalı çalışmaların tasnif edilmesi sürecinde her bir çalışma ayrı ayrı titizlikle incelenmiştir. Öncelikle makalelerin demografik özelliklerine ilişkin (yıl, üniversite, yazar sayısı) tasnif gerçekleştirilmiştir. Ardından çalışmaların araştırma metodolojisi, deseni, örnekleme yöntemi, örneklem grubu, veri toplama aracı ve analiz yöntemleri sınıflandırılmıştır. Verilerin tasnif işleminden sonra önce Excel programında kodlamalar yapılmış sonrasında ise frekans ve yüzde bilgileri verilerek yorumlanmıştır.

\section{Bulgular}

Bulgular kısmında ele alınan çalışmalara ilişkin değerlendirmeler iki başlık altında sunulmuştur. Öncelikle yapılan çalışmaların demografik özellikleri belirlenmiş, daha sonra ise metodolojik kurgularına ait bulgular sunulmuştur. Sunulan bulgular sayısallaştırılmış ve görselleştirilerek tablolara aktarılmıştır. 


\section{Yayımlanan Makalelere İlişkin Demografik Bulgular}

\begin{tabular}{lll}
\multicolumn{3}{c}{ Tablo 2: Yillara Göre Çalışmaların Dağılımı } \\
\hline Y1l & $\mathrm{f}$ & $\%$ \\
\hline $2005-2010$ & 1 & $\% 2.3$ \\
$2011-2015$ & 9 & $\% 21$ \\
$2016-2020$ & 33 & $\% 76.7$ \\
\hline Toplam & 43 & $\% 100$ \\
\hline
\end{tabular}

Tablo 2'de yıllara göre çalışmaların dağılımları sunulmuştur. Araştırma sonuçlarına göre en fazla çalışma 2016-2020 yılları arasında 33 (\%76.7) üretilmiştir. Daha sonra ise 2011-2015 yılları arasında 9 (\%21), 2005-2010 yılları arasında ise sadece 1 (\%2.3) makalenin yayımlandığ1 görülmektedir.

Tablo 3: Üniversitelere Göre Çalışmaların Dağılımı

\begin{tabular}{|c|c|c|}
\hline Üniversite & $\mathrm{f}$ & $\%$ \\
\hline Anadolu Üniversitesi & 3 & $\% 5.3$ \\
\hline $\begin{array}{l}\text { Dokuz Eylül } \\
\text { Üniversitesi }\end{array}$ & 3 & $\% 5.3$ \\
\hline Kastamonu Üniversitesi & 3 & $\% 5.3$ \\
\hline İnönü Üniversitesi & 3 & $\% 5.3$ \\
\hline Furat Üniversitesi & 2 & $\% 3.5$ \\
\hline Marmara Üniversitesi & 2 & $\% 3.5$ \\
\hline İstanbul Üniversitesi & 2 & $\% 3.5$ \\
\hline Adıyaman Üniversitesi & 2 & $\% 3.5$ \\
\hline $\begin{array}{l}\text { Erzurum Teknik } \\
\text { Üniversitesi }\end{array}$ & 2 & $\% 3.5$ \\
\hline Mersin Üniversitesi & 2 & $\% 3.5$ \\
\hline Sakarya Üniversitesi & 2 & $\% 3.5$ \\
\hline Bayburt Üniversitesi & 2 & $\% 3.5$ \\
\hline Bartın Üniversitesi & 2 & $\% 3.5$ \\
\hline Dumlupınar Üniversitesi & 2 & $\% 3.5$ \\
\hline Diğer Üniversiteler & 25 & $\% 43.8$ \\
\hline Toplam & 57 & $\% 100$ \\
\hline
\end{tabular}

Tablo 3'de yayımlanan makalelerin yazarlarının yer aldığı üniversite dağılımları ortaya konulmuştur. Yayımlanan çalışmaların yarısından fazlasında birden fazla üniversite ve yazarın olmasından dolayı toplam üniversite sayısı toplam makale sayısını geçmiştir. Elde edilen verilerin analizi neticesinde çalışmalarda en fazla Anadolu (3), Dokuz Eylül (3), Kastamonu (3) ve İnönü üniversitelerinin (3) yer aldığı görülmektedir. Bu dört üniversite adına yayımlanan çalışmaların toplamı 12'dir. Daha sonra ise 2'şer makale ile sırasıyla Firat, Marmara, İstanbul, Adıyaman, Erzurum Teknik, Mersin, Sakarya, Bayburt, Bartın ve Dumlupınar üniversiteleri gelmektedir. Bununla birlikte 2 araştırmadan az çalışması olan üniversiteler "diğer" kategorisi altında toplanmış ve diğer üniversitelerden yayımlanan makale sayısının 25 olduğu anlaşılmaktadır.

Tablo 4: Akademisyen Sayılarına Göre Çalışmaların Makale Dağılımwları

\begin{tabular}{lll}
\hline Unvan & $\mathrm{f}$ & $\%$ \\
\hline Tek Yazar & 10 & $\% 23.2$ \\
İki Yazar & 20 & $\% 46.5$ \\
Üç Yazar & 10 & $\% 23.2$ \\
Dört Yazar & 3 & $\% 7$ \\
\hline Toplam & 43 & $\% 100$ \\
\hline
\end{tabular}


Tablo 4'de yazar sayılarıyla ilgili bilgiler sunulmuştur. Buna göre yayımlanan makalelerin 20 tanesi (\% 46.5) iki yazarlı, yine 21 'de (\% 37.5) üç yazarlıdır. 56 makalenin 8'i ( \%14.3) dört yazarlı, 5'ide ( \% 9) tek yazarlıdır. Çalışmaların sadece 1'i ( \%1.7) beş yazarlıdır.

\section{Yürütülen Çalışmaların Yöntemleriyle İlgili Bulgular}

Tablo 5: Çalışmaların Yöntemlerine Göre Dağılımı

\begin{tabular}{lll}
\hline Araştırma Metodolojisi & f & $\%$ \\
\hline Nicel & 1 & $\% 2.3$ \\
Belirtilmemiş & 42 & $\% 97.7$ \\
\hline Toplam & 43 & $\% 100$ \\
\hline
\end{tabular}

Tablo 5'de araştırmalarda istifade edilen araştırma metodolojilerine yer verilmiştir. Elde edilen bulgulara göre yayımlanan 43 makalenin sadece 1 (\%2.3) tanesinde nicel araştırma yönteminden faydalanıldığı ifade edilmiştir. Ancak 43 (\%97.7) makalenin 42'sinde yönteme ait bilgi bulunmamaktadir.

Tablo 6: Araştırma Desenine Göre Çalışmaların Dağglımı

\begin{tabular}{lll}
\hline Araştırma Deseni & $\mathrm{f}$ & $\%$ \\
\hline Tarama & 2 & $\% 4.7$ \\
Olay Çalışması & 1 & $\% 2.3$ \\
Belirtilmemiş & 40 & $\% 93$ \\
\hline Toplam & 43 & $\% 100$ \\
\hline
\end{tabular}

Tablo 6'de çalışmalardaki araştırma desenlerine yer verilmiştir. Makalelerin 2'sinde (\%4.7) tarama, 1'inde (\%2.3) olay çalışması desenlerinden faydalanılmıştır. Yayımlanan makalelerin 40'ında (\%93) ise çalışma sürecinde hangi araştırma deseninden faydalanıldığına yönelik herhangi bir bilgi yer almamaktadır.

Tablo 7: Örnekleme Modeline Göre Çalışmaların Dağılımı

\begin{tabular}{lll}
\hline Örnekleme Yöntemi & $\mathrm{f}$ & $\%$ \\
\hline Evrenin Tamamı & 23 & $\% 53.5$ \\
Amaçlı & 1 & $\% 2.3$ \\
Kolay & 1 & $\% 2.3$ \\
Rastgele & 1 & $\% 2.3$ \\
Belirtilmemiş & 17 & $\% 39.5$ \\
\hline Toplam & 43 & $\% 100$ \\
\hline
\end{tabular}

Tablo 7'de yürütlen çalışmalarda kullanılan örnekleme yöntemlerine yer verilmiştir. Araștırmaların 23'ünde (\%53.5) evrenin tamamı ile çalışılırken, 1'inde (\%2.3) amaçlı, 1'inde (\%2.3) kolay ve yine 1 'inde (\%2.3) ise rastgele örnekleme yöntemi kullanılmıştır. 17 (\%39.5) çalışmada ise hangi örnekleme yönteminden yararlanıldığı belirtilmemiştir.

Tablo 8: Örneklem Gruplarına Göre Çalışmaların Göre Dağılımı

\begin{tabular}{lll}
\hline Örneklem Grupları & $\mathrm{f}$ & $\%$ \\
\hline Spor Kulüpleri & 36 & $\% 83.7$ \\
Üniversite Öğrencisi & 2 & $\% 4.7$ \\
Belirtilmemiş & 5 & $\% 11.6$ \\
\hline Toplam & 43 & $\% 100$ \\
\hline
\end{tabular}

Tablo 8'de çalışmalardaki örneklem gruplarına yer verilmiştir. Çalışmalarda en çok spor kulüpleri ile 36 (\%83.7) çalışıldığı görülmektedir. Daha sonra ise $2(\% 4.7)$ makalede üniversite öğrencileri çalışma grubu olarak belirlenmiştir. 5 (\%11.6) çalışmada ise hangi örneklem grubunun seçildiği belirtilmemiştir. 
Tablo 9: Veri Toplama Araçlarına Göre Çalışmaların Dağılımı

\begin{tabular}{lll}
\hline Veri Toplama Araçları & $\mathrm{f}$ & $\%$ \\
\hline Doküman İnceleme (Mali Tablolar) & 32 & $\% 74.4$ \\
Anket & 2 & $\% 4.7$ \\
Görüşme Formu & 1 & $\% 2.3$ \\
Belirtilmemiş & 8 & $\% 18.6$ \\
\hline Toplam & 43 & $\% 100$
\end{tabular}

Tablo 9'de çalışmalardaki veri toplama araçlarına yer verilmiştir. Makalelerin büyük bir kısmında çoğunluğunda (32, \%74.4) veri toplama aracı olarak Kamuoyu Aydınlatma Platformu'nda (KAP) yer alan mali tablolardan faydalanıldığı ve doküman inceleme yönteminin kullanıldığ anlaşılmaktadır. Daha sonra ise $2(\% 4.7)$ çalışmada anket, $1(\% 2.3)$ çalışmada ise görüşme formunun kullanıldığı görülmektedir. Yayımlanan çalışmaların 8'inde (\%18.6) ise veri toplama araçları ile ilgili herhangi bir bilgiye yer verilmemiştir.

Tablo 10: Çalışmaların Analiz Yöntemlerine Göre Dağılımı

\begin{tabular}{lll}
\hline Üniversite & $\mathrm{f}$ & $\%$ \\
\hline ANOVA & 4 & $\% 9.3$ \\
Regresyon Analizi & 4 & $\% 9.3$ \\
TOPSiS & 4 & $\% 9.3$ \\
Littlewood İki Sınıf Modeli & 3 & $\% 7$ \\
EGARCH Analizi & 3 & $\% 7$ \\
Entropi Analizi & 3 & $\% 7$ \\
Başa Baş Model Analizi & 3 & $\% 7$ \\
Oran Analizi & 2 & $\% 4.6$ \\
Diğer & 16 & $\% 37.2$ \\
Belirtilmemiş & 12 & $\% 28$ \\
\hline
\end{tabular}

Yayımlanan her bir çalışmada birden çok analiz yöntemi kullanıldığı için analiz yöntemi sayısı hem frekans hem de yüzde olarak toplam makale sayısından fazladır. Bununla birlikte çalışmalarda kullanılan her bir istatistiksel analizin yüzdelik hesaplaması da birbirinden bağımsız olarak yapılmıştır. Buna göre çalışmalarda en çok ANOVA (4), Regresyon (4) ve TOPSíS (4) analiz yöntemlerinin kullanıldığı görülmektedir. Daha sonra ise Littlewood iki sınıf modeli (3), EGARCH (3), Entrop analizi (3) ve Başa baş model analizi (3) gelmektedir. Araştırmalarda 2'den az analiz yöntemlerinin kullanıldığ çalışmalar "diğer" kategorisi altında toplanmıştır. Ayrıca 43 çalışmanın 12'sinde hangi analiz yöntemlerinin kullanıldığına yönelik herhangi bir bilgiye yer verilmemiştir.

\section{Tartışma}

$\mathrm{Bu}$ çalışmanın amacı, DERGIPARK sisteminde yer alan ve erişime açık olan bilimsel dergilerde 2005-2020 yılları arasında spor ekonomisi alanında Türkçe yayımlanan muhasebe finans temalı makalelerin yöntemsel eğilimlerini incelemektir. Bu amaca istinaden toplamda 30 dergide yayımlanan 43 makale incelenmiş yöntemsel eğilimlerine ilişkin bulgular sunulmuştur. Ancak spor ekonomisi ile ilgili yöntemsel eğilimlerin daha önce incelendiği herhangi bir çalışma bulunamamıştır.

\section{Spor Yönetimi ile İlgili Makalelerin Demografik Özellikleri}

Araştırmada incelenen spor ekonomisinde muhasebe finans temalı en fazla makalenin 20162020 yılları arasında 33 (\%76.7) üretildiği görülmektedir. Daha sonra ise 2011-2015 yılları arasında 9 (\%21), 2005-2010 yılları arasında ise sadece 1 (\%2.3) makalenin yayımlandığ 1 görülmektedir. Yayımlanan makalelerin toplamda 57 üniversiteden geldiği belirlenmiştir. Elde edilen verilerin analizi neticesinde çalışmalarda en fazla Anadolu (3), Dokuz Eylül (3), Kastamonu (3) ve İnönü 
üniversitelerinin (3) yer aldığı görülmektedir. Bu dört üniversite adına yayımlanan çalışmaların toplamı 12'dir. Daha sonra ise 2'şer makale ile sırasıyla Fırat, Marmara, İstanbul, Adıyaman, Erzurum Teknik, Mersin, Sakarya, Bayburt, Bartın ve Dumlupınar üniversiteleri gelmektedir. Bununla birlikte 2 çalışmanın altında kalan üniversiteler "diğer" kategorisi altında toplanmış ve diğer üniversitelerden yayımlanan makale sayısının 25 olduğu anlaşılmaktadır. Yayımlanan makalelerin 20 tanesi (\% 46.5) iki yazarlı, yine 21'de (\% 37.5) üç yazarlıdır. 56 makalenin 8'i ( \%14.3) dört yazarlı, 5'ide ( \% 9) tek yazarlıdır. Yayımlanan makalelerden sadece 1'i ( \%1.7) beş yazarlıdır.

\section{Spor Yönetimi ile İlgili Makalelerin Metodolojik Özellikleri}

Çalışmaların araştırma yöntemlerine ilişkin bulgular incelendiğinde elde edilen bulgulara göre yayımlanan 43 makalenin sadece 1 tanesinde nicel araştırma yönteminden faydalanıldığı görülmektedir. Ancak çalışmaya ilişkin en dikkat çekici bulgulardan bir tanesi, 43 makalenin 42'sinde hangi araştırma yönteminden yararlanıldığına ilişkin herhangi bir bilgi yer almamasıdır. Oysa çalışmaların metodolojik kurgularının net bir şekilde ifade edilmesi araştırmaarın bilimsel niteliğine önemli katkılar sunabilir. Çünkü bir çalışmanın hangi araştırma yöntemi ile yürütüldüğünün açık bir şekilde ortaya konulması çalışmanın içeriği ve kapsamı hakkında fikir verebilir (Atalay, 2017).

İncelenen 43 çalışmanın 42'sinde araştırmaların hangi yöntemle yürütüldüğünün belirtilmemesi, bu makalelerin niteliksel açıdan zayıf kalmasına sebep olabilir. Yürütülen bu çalışmada elde edilen bulguların aksine başta eğitim bilimleri alanı olmak üzere fen ve sosyal bilimlerde yapılan metodolojik inceleme çalışmalarında araştırmaların hangi yöntemle (Nitel, Nicel, Karma) yürütüldüğünün açık, net ve eksiksiz bir şekilde ortaya konulduğu görülebilir (Çubukçu vd., 2016; Kozikoğlu ve Senemoğlu, 2015; Günay ve Aydın, 2015; Dikmen ve Demirer, 2016; Altuntaş ve Turan, 2016; Uyar, 2017).

Spor ekonomisi ile ilgili makalelerin hangi araştırma deseni ile yürütüldügüne dair bulgular incelendiğinde, 43 makalenin 40'ında araştırma yöntemlerinde olduğu gibi çalışmaların hangi desenle yürütüldüğüne dair bir bilgi bulunmamaktadır. Bununla birlikte 2 çalışma tarama, 1 çalışma ise olay çalışması deseni ile yürütülmüştür. Çalışmaların araştırma yöntem ve desenleri, okuyuculara genel bir çerçeve çizerken, araştırmaların kapsam ve bilimsel niteliğini ortaya koyan bir unsurdur. Dolayısı ile 40 makalede kullanılan araştırma desenine ilişkin bir bilginin olmaması oldukça dikkat çekicidir. Ve bu durum spor ekonomisi literatürünün niteliksel özelliklerini zayıflatabilir. Ancak özellikle sosyal bilimler ve eğitim bilimleri çalışmalarına bakıldığında araştırma desenlerinden en çok tarama deseninin tercih edildiği ve bunun da çalışmalarda ayrıntılı bir şekilde ifade edildiği görülmektedir (Üstündağ, 2013; Seçer vd., 2014; Aydın ve Uysal, 2014; Turan vd, 2014; Kurtoğlu ve Seferoğlu, 2013; Akgün vd., 2016; Ataseven ve Oğuz, 2015).

Makalelerde örneklem gruplarının belirlenmesinde hangi yöntemlerin kullanıldığına ilişkin bulgular incelendiğinde, çalışmaların 23'ünde evrenin tamamı ile çalışılırken, 1'inde amaçlı, 1'inde kolay ve yine 1'inde ise rastgele örnekleme yöntemi kullanılmıştır. 17 çalışmada ise hangi örnekleme yönteminden yararlanıldığ 1 belirtilmemiştir. Çalışmaların yarısından fazlasında evrenin tamamına ulaşılmıştır. Burada makale içerikleri dikkate alındığında daha çok Borsa İstanbul'da (BİST) işlem gören dört spor kulübüne (Fenerbahçe, Galatasaray, Beşiktaş ve Trabzonspor) ait mali tabloların irdelendiği anlaşılmaktadır. Dolayısıyla örneklem seçmekten ziyade bu dört kulüp üzerinden makalelerin üretildiği söylenebilir. Daha sonra ise 3 çalışmada amaçl, kolay ve rastgele örnekleme yöntemlerinin tercih edildiği anlaşılmaktadır. Ancak 43 makalenin 17'sinde hangi örnekleme yönteminin kullanıldığına dair bir bilgiye ulaşılamamıştır. Yine bu araştırmanın aksine eğitim, sosyal ve fen bilimleri ile ilgili literatürde yer alan çalışmalarda daha çok rastgele, tesadüfi ve amaçlı örnekleme yöntemlerinden yararlanıldığı görülmektedir (Kurt ve Erdoğan, 2015; Biçer, 2017; Babur vd., 2016; Selçuk vd., 2014; Yüksel vd., 2016). 
Spor ekonomisi alanında üretilen makalelerde hangi örneklem grupları ile çalışıldığına ilişkin bulgulara göre makalelerde en çok spor kulüpleri ile (36) çalışıldığı görülmektedir. Daha sonra ise 2 makalede üniversite öğrencileri çalışma grubu olarak belirlenmiştir. 5 çalışmada ise hangi örneklem grubunun seçildiği belirtilmemiştir. Yukarıda da ifade edildiği üzere çalışma içerikleri dikkate alındığında spor kulüplerinin mali yapılarının analizleri esas araştırma konusu olarak karşımıza çıkmaktadır. Dolayısı ile çalışmalarda ağırlıklı olarak spor kulüplerinin örneklem grubu olarak tercih edilmesi öne çıkmaktadır. Özellikle dört spor kulübünün borsada işlem görmesi ve mali kayıtlarının ulaşılabilir olması bu durumu açıklar niteliktedir.

Veri toplama araçları ile ilgili buldulara bakıldığında ise makalelerin büyük çoğunluğunda (32) veri toplama aracı olarak Kamuoyu Aydınlatma Platformu'nda (KAP) yer alan mali tablolardan faydalanıldığ1 ve doküman inceleme yönteminin kullanıldığı görülmektedir. Daha sonra ise 2 çalışmada anket, 1 çalışmada ise görüşme formunun kullanıldı̆̆ görülmektedir. Yayımlanan çalışmaların 8'inde ise hangi veri toplama aracının kullanıldığına ilişkin herhangi bir bilgiye yer verilmemiştir. Yine çalışma içerikleri dikkate alındığında borsada işlem gören ve mali kayıtları erişime açık olan spor kulüpleri ile çalışıldığından KAP'da yer alan mali kayıtların irdelenmesi ve doküman inceleme yönteminin kullanılması doğal bir durum olarak karşılanabilir. Ancak sosyal bilimler başta olmak üzere mevcut literatüre bakıldığında çoğunlukla veri toplama aracı olarak anketin kullanıldığı görülmektedir (Çelik, 2016; Wassink ve Sadi, 2016; Şimşek vd., 2008; Gülbahar ve Alper, 2009; Akın vd., 2017; Doğru vd., 2012; Akın ve Onat, 2016). Yukarıda da ifade edildiği üzere makalelerin içerikleri finansal tablolardan çıkarımlar ve değerlendirmeler yapmak üzere kurgulandığından anket yönteminin tercih edilmemesi beklenen bir durumdur.

Son olarak incelenen çalışmalarda kullanılan analiz yöntemlerine bakıldığında, en çok ANOVA (4), Regresyon (4) ve TOPSİS (4) analiz yöntemlerinin kullanıldığı görülmektedir. Akabinde ise daha çok finansal ve muhasebeye ilişkin analiz yöntemleri olan Littlewood iki sınıf modeli (3), EGARCH (3), Entrop analizi (3) ve Başa baş model analizi (3) yöntemlerinin kullanıldığ anlaşılmaktadır. Ayrıca 43 çalışmanın 12'sinde hangi analiz yöntemlerinin kullanıldığına yönelik herhangi bir bilgiye yer verilmemiştir. Çalışmaların disiplinler arası olması (spor ve ekonomi) sebebi ile finansal analiz yöntemlerinin tercih edilmesi, eğitim, sosyal ve fen bilimlerine göre farkll1ık arz etmektedir Oysa özellikle sosyal bilimler ve eğitim alanında betimleme ve karşılaştırmaya yönelik analizlerin gerçekleştirildiği mevcut literatürde ortaya konulmaktadır (Çakmak vd., 2016; Akaydın ve Çeçen, 2015; Öngöz vd., 2016; Ozan ve Köse, 2014; Yalçın vd., 2015).

\section{Sonuc}

DERGIPARK sisteminde yer alan ve erişime açık olan bilimsel dergilerde spor ekonomisi alanında Türkçe yayımlanan muhasebe finans temalı makalelerin yöntemsel eğilimlerinin incelendiği bu çalışmada şu sonuçlara ulaşılmıştır:

- Metodoloji bölümleri incelenen 43 makalenin 42'sinde hangi araştırma yönteminin, 40'ında hangi araştırma deseninin kullanıldığı ile ilgili herhangi bir bilgiye yer verilmemiştir. Ayrıca 23 çalışmada örneklem seçme yoluna gidilmemiş ve evrenin tamamına ulaşılmıştır.

- Çalışmalarda örneklem grubu olarak çoğunlukla spor kulüpleri belirlenmiş ve bu kulüplere ait mali tablolar incelenmiştir.

- $\quad$ Makalelerde çoğunlukla mali tabloların incelenmesi amaci ile veri toplama aracı olarak doküman inceleme yönteminin tercih edildiği saptanmıştır.

- $\quad$ Elde edilen verilerin analizinde ise finansal analiz yöntemlerinin (Littlewood iki sinıf modeli, EGARCH, Entropi analizi ve Başa baş model analizi) yanı sıra ANOVA, Regresyon ve TOPSİS yöntemlerinin tercih edildiği belirlenmiştir. 
Bütüncül bir değerlendirme yapmak gerekirse, spor ekonomisi alanında muhasebe finans temalı çalışmaların metodolojik yapılarının yetersiz ve eksik kaldığı söylenebilir. Özellikle hangi araştırma yöntem ve deseninin kullanıldığına dair bilgi eksikliği çalışmaların yöntemsel yapılarını zayıflatmaktadır. Nitekim Tuncel (2008), de bu çıkarımı desteklemekte ve spor bilimlerinde üretilen bilimsel çalışmalarda yöntem kısmının eksiksiz bir şekilde sunulmadığını, çoğu zaman uygun araştırma yöntemlerinin de kullanılmadığını ifade etmektedir. Özellikle eğitim, sosyal ve fen bilimleri alanlarında yer alan metodolojik inceleme çalışmaları ile kıyaslandığında spor ekonomisi ile ilgili çalışmaların yöntemsel yapılarının zayıf kaldığı söylenebilir. Literatürün niteliksel yapısının güçlendirilmesi adına bilimsel araştırma yöntemlerinin daha etkili bir şekilde kullanılması elzemdir.

\section{Kaynakça}

Akaydın, Ş. \& Çeçen, M.A. (2015). Okuma becerisiyle ilgili makaleler üzerine bir içerik analizi. Eğitim ve Bilim Dergisi, 40(178), 183-198.

Akgün, M., Yücekaya, G.K. \& Dışbudak, K. (2016). Türkiye'de akıllı tahta kullanımına yönelik araştırmalar: Bir içerik analizi çalışması. Gazi Eğitim Fakültesi Dergisi, 36(1), 73-94.

Akın, A., Ulukök, E. \& Arar, T. (2017). İş-yaşam Dengesi: Türkiye'de yapılan araştırmalara yönelik teorik bir inceleme. Afyon Kocatepe Üniversitesi, İ̈BF Dergisi, 19(1), 113-124.

Akın, O. \& Onat, O.K. (2016). Modern maliyet yönetimi teknikleri ve 2000-2014 döneminde bu teknikleri ele alan lisansüstü tezlere dair bir değerlendirme. Mehmet Akif Ersoy Üniversitesi IIBF Dergisi, 3(1), 6-15.

Altuntaş, E.Ç. \& Turan, S.L. (2016). Çevre eğitiminde 2010-2015 yılları arasında yapılan araştırmalar ve eğilimler. Eğitim ve Toplum Araştırmaları Dergisi, 3(2), 1-14.

Atalay, A. (2017). Türkiye'de spor yönetimi araştırmalarındaki eğilimler: Bir içerik analizi. Turkish Studies - International Periodical For The Languages, Literature and History of Turkish or Turkic, Volume 12/29, p. 107-128. http://dx.doi.org/10.7827/TurkishStudies.12512

Ataseven, N. \& Oğuz, A. (2015). Türkiye'de öğrenme stilleri konusunda yapılan tezlerin incelenmesi. Eğitim ve Ögretim Araştırmaları Dergisi, 4(3), 192-205.

Ayan, S. \& Ergin, M. (2017). Özel gereksinimli bireylerin fiziksel aktivite programlarına katılımlarını engelleyen faktörlerin incelenmesi. International Periodical for the Languages, Literature and History of Turkish or Turkic Volume 12/25, p. 149-168. www.turkishstudies.net. http://dx.doi.org/10.7827/TurkishStudies.12231

Aydın, A. \& Uysal, Ş. (2014). Türkiye' de eğitim yönetimi teftişi planlaması ve ekonomisi alanındaki doktora tezlerinin incelenmesi. Abant İzzet Baysal Üniversitesi Ĕgitim Fakültesi Dergisi, 14(1), 177-201.

Babur, A., Kiper, A., Çukurbaşı, B., Özer, Ö.A., Tonbuloğlu, İ., Küçük, Ş., Demirhan, E., Güngören, Ö.C., Kıyıc1, M. \& Horzum, M.B. (2016). 2009-2013 yılları arasında uzaktan eğitim dergilerinde yayınlanan makalelerin yöntemsel açıdan incelenmesi. Sakarya University Journal of Education, 6(1), 123-140.

Bayraktar, C. (2003). Sosyal yapı özelliklerinin spora etkisi. Uludă̆ Üniversitesi Eğitim Fakültesi Dergisi, 17(1), 19-36.

Biçer, N. (2017). Yabancılara Türkçe öğretimi alanında yayınlanan makaleler üzerine bir analiz çalışması. Pamukkale Üniversitesi Sosyal Bilimler Enstitüsü Dergisi, 27, 236-247. 
Chalip, L. (2006). Toward a distinctive sport management discipline. Journal of Sport Management, $20(1), 1-21$.

Cunningham, G. \& Mahoney, K. (2004). Self-efficecy of part-time employees in university athletics: The influence of organizational commitment, valence of training and training motivation. Journal of Sport Management, 18(1), 59-73.

Çakmak, E.K., Özüdoğru, G., Bozkurt, Ş.B., Ülker, Ü., Ünsal, N.Ö., Boz, K., Bozkurt, Ö.F,. Sönmez, E.E., Kaya, C.B., Karaca, C., Bahadır, H. \& Gül, H.Ü. (2016). 2014 y1lında eğitim teknolojileri alanındaki yayımlanan makalelerin incelenmesi. Ĕgitim Teknolojisi Kuram ve Uygulama, 6(1), 80-108.

Çelik, N. (2016). Yenilikçilik konusunda yapılan doktora tezlerinin içerik analizi yöntemiyle değerlendirilmesi. Uluslararası Ekonomi ve Yenilik Dergisi, 2(1), 29-42.

Çubukçu, Z., Yılmaz, B.Y. \& İnci, T. (2016). Karşılaştırmalı eğitim programları araştırma eğilimlerinin belirlenmesi-bir içerik analizi. Uluslararası Türkçe Edebiyat Kültür Eğitim Dergisi, 5, 446-468.

Darnell, S.C. (2010). Power politics and "sport for development and peace": Investigating the utility of sport for international development. Sociology of Sport Journal, 27(1), 54-75.

Deery, M \& Jogo, L. (2005). The management of sport tourisim. Sport in Society Culture Commerce Media Politics, 8(2), 378-389.

Devecioğlu, S. (2005). Türkiye'de spor sektörü stratejilerinin geliştirilmesi. Verimlilik Dergisi, 2, $117-134$

Dikmen, C.H. \& Demirer, V. (2016). Türkiye'de teknolojik pedagojik alan bilgisi üzerine 2009-2013 yılları arasında yapılan çalışmalardaki eğilimler. Turkish Journal of Education, 5(1), 33-47.

Doğru, M., Gençosman, T., Ataalkın, A.N. \& Şeker, F. (2012). Fen bilimleri eğitiminde çalışılan yüksek lisans ve doktora tezlerinin analizi. Türk Fen Eğitimi Dergisi, 9(1), 49-64.

Falkingham R.T. \& Reeves, R. (1998). Context analysis: A technique for analysing research in a field, applied to literatüre on the management of R\&D et the section level. Scientometrics, $4(2), 97-121$.

Gökmen, Ö.F., Uysal, M., Yaşar, H., Kırksekiz, A., Güvendi, G.M. \& Horzum, M.B. (2017). Türkiye'de 2005-2014 yılları arasında yayınlanan uzaktan eğitim tezlerindeki yöntemsel eğilimler: Bir içerik analizi. Eğitim ve Bilim Dergisi, 42(189), 1-25.

Gülbahar, Y.\& Alper, A. (2009). A content analysis of the studies in instructional Technologies area. Ankara University Journal of Faculty of Educational Sciences, 42(2), 93-111.

Günay, R. \& Aydın, H. (2015). Türkiye'de çok kültürlü eğitim ile ilgili yapılan araştırmalarda eğilim: Bir içerik analizi çalışması. Eğitim ve Bilim Dergisi, 40(178), 1-22.

Güngör. A ve Uzun Kocamış, T. (2018). Halka açık futbol kulüplerinde finansal performansın topsis yöntemi ile analizi: İngiltere uygulaması. Hitit Üniversitesi Sosyal Bilimler Enstitüsü Dergisi, 11(3), 1846-1859. doi:10.17218/hititsosbil.450325

Karadağ, E. (2010). Eğitim bilimleri doktora tezlerinde kullanılan araştırma modelleri: Nitelik düzeyleri ve analitik hata tipleri. Kuram ve Uygulamada Ĕ̈itim Yönetimi, 16(1), 49-71.

Karakaya, Y.E. \& Tel, M. (2014). Küreselleşme çağı ve yükseköğretimde spor bilimleri üzerine. Turkish Studies - International Periodical For The Languages, Literature and History of Turkish or Turkic Volume 9/11 Fall 2014, p. 321-331. 
Koziklioğlu, İ. \& Senemoğlu, N. (2015). Eğitim programları ve öğretim alanında yapılan doktora tezlerinin içerik analizi: (2009-2014). Eğitim ve Bilim Dergisi, 40(182), 29-41.

Köylü, M.K., Şişman, M.Y. \& Yücel, A. (2017). Oyunlarda galibiyet/ mağlubiyet ve hisse senetleri: bir futbol kulübünün hisse senet performansına ilişkin bir analiz. Al-Farabi Uluslararası Sosyal Bilimler Dergisi, 1(3), 333-354.

Kurt, A. \& Erdoğan, M. (2015). Program değerlendirme araştırmalarının içerik analizi ve eğilimleri; 2004-2013 yılları arası. Eğitim ve Bilim Dergisi, 40(178), 199-224.

Kurtoğlu, M. \& Seferoğlu, S.S. (2013). Öğretmenlerin teknoloji kullanım ile ilgili Türkçe kaynaklı dergilerde yayımlanmış makalelerin incelenmesi. Journal of Instructional Technologies \& Teacher Education, 2(3), 1-10.

Miragaia, D.A.M. \& Soares, J.A.P. (2017). Higher education in sport management: A systematic review of research topics and trends. Journal of Hospitality Leisure Sport and Tourisim Education, 21, 101-116.

Ozan, C. \& Köse, E. (2014). Eğitim programları ve eğitim alanındaki araştırma eğilimleri. Sakarya University Journal of Education, 4(1), 116-136.

Öngöz, S., Aydın, Ş. \& Aksoy, D.A. (2016). Türkiye'de eğitim bilimleri alanında yapılan çoklu ottam konulu lisansüstü tezlerin eğilimleri. Journal of Instructional Technologies \& Teacher Education, 5(1), 45-58.

Pitney, W.A., Issley, P. \& Rintala, J. (2002). The professional socialization of certified athletic trainers in the national colligiate athletic association division. Journal of Athletic Training, 37(1), 63-70.

Scholtens, B. \& Peenstra, W. (2009). The effect of football matches on stock market returns. Applied Economics, 41(25), 3231-3237.

Seçer, İ., Ay, İ., Ozan, C. \& Yılmaz, B.Y. (2014). Research trends in the field of guidance and psychological counseling: A content analysis. Turkish Psychological Counseling and Guidance Journal, 5(41), 49-60.

Selçuk, Z., Palanc1, M., Kandemir, M. \& Dündar, H. (2014). Eğitim ve bilim dergisinde yayınlanan araştırmaların eğilimleri: İçerik analizi. Eğitim ve Bilim Dergisi, 39(173), 430-451.

Skinner, F., Edwards, A. \& Corbett, B. (2015). Research Methods for Sport Management. London: Routledge.

Şimşek, A., Özdamar, N., Becit, G., Kılıçer, K., Akbulut, Y. \& Yıldırım, Y. (2008). Türkiye'deki eğitim teknolojileri araştırmalarında güncel eğilimler. Selçuk Üniversitesi Sosyal Bilimler Enstitüsü Dergisi, 19, 439-458.

Tavşancıl, E. \& Aslan, E. (2001). İçerik Analizi ve Uygulama Örnekleri. İstanbul: Epsilon Yayınları.

Tuncel, S.D: (2008). Uluslararas1 yayınlarda nitelik: Bazı spor bilimleri dergilerine Türkiye'den gönderilen araştırmaların niteliği. Spormetre, 6(3), 125-127.

Turan, S., Karadağ, E., Bektaş, F. \& Yalçı, M. (2014). Türkiye'de eğitim yönetiminde bilgi üretimi: Kuram ve Uygulamada Eğitim Yönetimi Dergisi 2003-2013 yıllarının incelenmesi. Kuram ve Uygulamada Ë̆itim Yönetimi Dergisi, 20(1), 93-119.

Türkmen, M. \& Varol, R. (2017). İmam hatip ortaokullarındaki öğrencilerin beden eğitimi ve spor dersine ilişkin tutumlarının araştırılması (Bartın il örneği). Turkish Studies-International Periodical for the Languages, Literature and History of Turkish or Turkic Volume 12/25, p. 749-762. www.turkishstudies.net, http://dx.doi.org/10.7827/TurkishStudies.12045 
Uluyol, O. (2014). Süper lig futbol kulüplerinin finansal performans analizi. Journal of Yasar University, 9(34), 5716-5731.

Uyar, M.Y. (2017). Eğitim programları ve öğretim alanına yönelik bir dergideki araştırmalara ilişkin bir içerik analizi: 2002-2015. Kastamonu Ĕ̈itim Dergisi, 25(3), 1009-1024.

Üstündağ, D.A. (2013). Türkiye'de bilgisayar ve öğretim teknolojileri eğitimi alanındaki yüksek lisans tezlerinin araştırma eğilimleri. Eğitim Teknolojisi Kuram ve Uygulama, 3(1), 55-73.

Wassink, F.K. \& Sadi, Ö. (2016). Türkiye'de fen bilimleri eğitimi yönelimi: 2005-2014 yılları arası bir içerik analizi. Illköğretim Online, 15(2), 594-614.

Yalçı, S., Yavuz, H.Ç. \& Dibek, M.İ. (2015). En yüksek etki faktörüne sahip eğitim dergilerindeki makalelerin içerik analizi. Eğitim ve Bilim Dergisi, 40(182), 1-28.

Yetim, A. (2000). Sporun sosyal görünümü. Gazi Üniversitesi Beden Eğitimi ve Spor Bilimleri Dergisi, 5(1), 63-72.

Yıldırım, A. ve Şimşek, H. (2016). Sosyal Bilimlerde Nitel Araştırma Yöntemler. Seçkin Yayıncılık.

Yiamauyiannis, A., Bower, G.G., Williams, J., Gentile, D. \& Alderman, H. (2013). Sport management education: Accreditation accountability and direct learning outcome assessments. Sport Management Education Journal, 7(1), 51-59.

Yüksel, S., Gündoğdu, K., Akyol, B. \& Vural, R.K. (2016). Hayat boyu öğrenme konusunda yayımlanan tez ve makalelere ilişkin bir içerik analizi: 2000-2015. Erzincan Üniversitesi Ĕ̈itim Fakültesi Dergisi, 18(2), 1491-1505. 